\title{
Finding \\ my voice
}

\section{Alison Williams}

In 2015, shortly after starting work on the EqualBITE project, I attended a Cabaret of Dangerous Ideas (CODI) session at the Edinburgh Fringe entitled Women! Science is still not for you! '. We were discussing the real issue of what a female postgraduate student might do when her male supervisor or professor spends most of his time addressing her breasts rather than her face (the presenter's very effective response to her professor had been: "Could you please talk to the bit of me that thinks?") when from the audience a young male voice said: "What are you going on about? It's a perfectly natural human response." I was dumbfounded. My (faulty) memory was that no one challenged him directly. Nor did I. I felt deeply uncomfortable, but couldn't find my voice; I just didn't have the words I needed to deal with it.

Looking up 'dumbfounded' in the Collins English Dictionary ${ }^{2}$, I found the following synonyms:

Amazed, stunned, astonished, confused, overcome, overwhelmed, staggered, thrown, startled, at sea, dumb, bewildered, astounded, breathless, confounded, taken aback, speechless, bowled over (informal), nonplussed, lost for words, flummoxed, thunderstruck, knocked sideways (informal), knocked for six (informal).

I was all of those, and angry and frustrated too. This recipe chronicles how, over the time of being involved with the EqualBITE project I have learned about myself as well as about the many aspects of gender, feminism and outstanding women I have been studying. Intersubjectivity, what Reinharz calls "a circular process: the woman doing the study learns about herself as well as about the woman she is studying" (1992, p. 127), has enabled me to change and continue to do so - through reflecting on myself and my own standpoint as an engaged researcher, and as a continually learning and growing person. And the recipe ends with how I finally found my voice.

\section{Ingredients}

- Provocation (something entirely unexpected/jarring/wrong-footing).

- Rage and embarrassment.

- Good friends and colleagues.

\section{Method}

I found the three A's approach to behaviour change a useful one:

\section{Awareness \\ Acceptance \\ Action}

Until I became aware of my situation and response to it, and accepted the reality, I couldn't act or make any significant or lasting changes to either the situation or my response. 
1. Awareness of the provocation, and my rage and embarrassment. I realised that I was doing the classic goldfish manoeuvre of opening and closing my mouth repeatedly, looking around the room to see if anyone else would pick up and respond to the comment, dumbfounded (lost for words, dumb, speechless) when no one did.

\section{Acceptance that I don't know what} to do or say. On the way home I asked myself what I should have said l'esprit d'escalier (see Unravelling rhetoric) - and realised that I didn't have a clue. What should I do? Where might I find the vocabulary?

3. Action: Asking other people for advice and possible phrases. I asked my partner when I got home, still fizzing; I asked my colleagues and friends, female and male. Responses ranged from people who didn't know what to say, to people who knew only too well what they might say, stopping (just) short of violence.

Suggestions included:

- The metaphorical: "Hunger is a perfectly natural human response but you don't go about snatching sandwiches from other people's plates."

- The stereotypical: "Typical male comment - that's all men ever think about. Every seven seconds, isn't it?"
- The confrontational: "Don't you go bringing that kind of sexist thinking into this situation."

But none of the suggestions felt right - the possible responses, I felt, drew me into the same space of polarisation and disagreement as the original speaker. I wanted something that would challenge and reframe the comment in my own mind, and potentially in his (or her) mind too.

Then a friend and colleague suggested a response that does both by putting the initial statement into context:

$$
\begin{aligned}
& \text { Yes, it may be a biological } \\
& \text { response. It is neither appropriate } \\
& \text { nor respectful in a professional, } \\
& \text { or any other, context. }
\end{aligned}
$$

Setting the statement in its professional and public context challenges the speaker to rethink their own assumptions and perspective. As the philosopher Lynne Tirrell observes: "Feminist philosophy of language takes seriously the interplay between content and context" (Tirrell, 2000, p. 144).

Initially I thought that what I needed was a battery of responses to use in any situation, and to practice them out loud until they became natural (usually in the car, rehearsing the phrase over and over until it became automatic). 
The first draft of this recipe concluded:

Now l'm looking for someone to say something sexist in my hearing, so that I can practise my new vocabulary. Volunteers anyone?

Since then there have been four times - all in social rather than professional situations - when a man has said something to me that was outrageously sexist (misogynist and/or homophobic). Once again, the shocking nature of the comments has left me dumbfounded (speechless, bowled over (informal), nonplussed, lost for words, flummoxed) in the same mixture of rage and embarrassment as before, and my responses have been patchy. Again I went back to asking friends and colleagues, and found another approach which I have used successfully - speak from "I".

When you... I feel... In future...

Savigny (2014) describes how "feminism as praxis enables women to 'speak out', have their voices heard, and in so doing, question existing structures of power. This in turn provides a mechanism through which change and agency are possible" (2014, p. 24). Learning to 'speak out' is a long hard journey for men as well as women (see Allies in the classroom) who have been brought up to accept the status quo and not to make waves (see The double bind).

As Solnit (2012) says: "Having the right to show up and speak are basic to survival, to dignity, and to liberty. I'm grateful that, after an early life of being silenced, sometimes violently, I grew up to have a voice, circumstances that will always bind me to the rights of the voiceless.".

In 2017, at an event given by a venerable academic institution (not this one), my neighbour during dinner moved - in equal measure with the red wine - from a pleasant conversation about my work on this book, to the embarrassingly personal. This time, eighteen months after the first incident, I found the words I needed: "When you make remarks like that, I feel very uncomfortable, and please stop it now." But was met by the standard defence: "It's a joke".

The after-dinner speeches thankfully intervened and afterwards I moved seats with the coffee, only to be pursued, a handshake forced on me, and then appallingly - his finger run down the back of my trapped hand. This time I was able to tell him clearly that he had crossed a line; he left smartly. I wrote, setting out briefly how I felt he had broken the institution's guidelines, and had a letter of apology within the week.

But the experiences we have are not just of being worn down; these experiences also give us resources. What we learn from these experiences might be how we survive these experiences. (Ahmed, 2017, p. 235) 
Finally, things are changing. People change. Cultures change: "Coffee-room conversations can be dangerous ground. Now, discriminatory talk is called out and challenged by colleagues. You wouldn't have seen this 10 years ago" (Leadership perspectives on gender equality), the author of the recipe Damning with faint praise observes that her experience has not been repeated, and the women students in Edinburgh College of Art talk of the safety they feel within the studios to express themselves and their ideas (Perspectives from students).

Finding and building my voice is a work in progress, and I continue to work at it, and to move beyond dumbfounded.

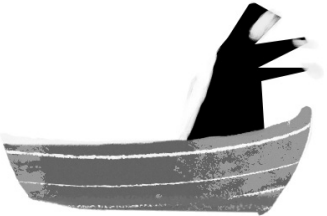

\section{Online references}

' http://codi.beltanenetwork. org/event/codi-2015-womenscience-is-still-not-for-you-2/

${ }^{2}$ https://www.collinsdictionary. com/dictionary/englishthesaurus/dumbfounded

I recently met Pam Cameron, one of the 2015 CODI presenters, and asked how she remembered responding to the heckler. Her reply: "It is human nature to notice an attractive person. However, whilst it's "being human" to notice (and I certainly notice an attractive man), it's neither acceptable nor professional to stare at breasts, bottoms or crotches! It's inappropriate behaviour for any workplace and it's intimidating coming from someone in a more senior position.

I would expect anyone to be able to separate out their appreciation of an attractive person, put that to one side, and engage with them as simply another human being, without leering!"

She continued: "I'm reasonably sure I didn't say the last piece, in italics, from the stage but it's how I subsequently deal with the "human nature" defence of lecherous behaviour." 